Virginia Commonwealth University vCU Scholars Compass

2016

\title{
Connecting Best Practices in Public Relations to Social Media Strategies for Academic Libraries
}

Bettina Peacemaker

Virginia Commonwealth University, bjpeacemaker@vcu.edu

Sue Robinson

Virginia Commonwealth University, srobinson26@vcu.edu

Emily Hurst

VirginiaCommonwealth University, ejhurst@vcu.edu

Follow this and additional works at: http://scholarscompass.vcu.edu/libraries_pubs

Part of the Library and Information Science Commons

\section{Downloaded from}

http://scholarscompass.vcu.edu/libraries_pubs/35

This Article is brought to you for free and open access by the VCU Libraries at VCU Scholars Compass. It has been accepted for inclusion in VCU Libraries Faculty and Staff Publications by an authorized administrator of VCU Scholars Compass. For more information, please contact libcompass@vcu.edu. 


\title{
Connecting Best Practices in Public Relations to Social Media Strategies for Academic
}

\section{Libraries}

Bettina Peacemaker, Virginia Commonwealth University Libraries, bjpeacemaker@vcu.edu Sue Robinson, Virginia Commonwealth University Libraries, srobinson26@vcu.edu Emily J. Hurst, Virginia Commonwealth University Libraries, ejhurst@vcu.edu

\begin{abstract}
Academic libraries worldwide use social media to inform and connect with users. VCU Libraries is no different and must keep up with rapidly evolving platforms and user expectations. When our presence stretched across 22 channels, we needed to ensure social media efforts were managed in the most effective and efficient manner possible. To develop a research-based, unified vision for communication for new media, we scanned the literature in the library and public relations fields and then surveyed librarians to address identified gaps. Based on results, we offer recommendations focused on best management practices and strong content strategies.
\end{abstract}

Keywords: social media, outreach, public relations, academic libraries, content strategy, social media strategy

\section{Introduction}

Are we approaching our social media planning, management and growth in the right ways? What can we learn about best practices from the public relations industry and from our academic library peers? How can we more effectively and efficiently manage these channels within the constraints of our time, expertise, and human resources? These were the questions 
Virginia Commonwealth University (VCU) Libraries faced a decade after it first started working with social media, and they are questions that many academic libraries are facing as they struggle to effectively engage audiences within a rapidly evolving social media landscape. In order to build a strong, research-based strategy, we started with a review of the library literature and of current practice in the public relations community. The scan revealed some common themes and helped us develop a survey to address gaps in our understanding, and more importantly to answer our questions regarding future content strategies and management of new media.

\section{VCU Libraries' meandering path to social media management}

VCU Libraries' first foray into social media was a news blog in 2005-06. YouTube, Facebook, and Flickr followed in 2008 and Twitter in 2009. Instagram and Tumblr were added in 2014-15, as well as a Twitter feed for online exhibits. Our social media footprint now includes 22 channels. Given this context, one of the most pressing questions is how do we organize and manage these communications media?

We have followed an uneven path in governance and management of new media. In 2008, the Tompkins-McCaw Library for the Health Sciences, one of the two main VCU libraries, formed a social media interest group. It set guidelines and an approval process for postings. That practice later gave way to a flexible, communal system of postings organized by a committee. In comparison, the posts from James Branch Cabell Library, the other primary library, came from an ad hoc group that posted as interest or time allowed. No established goals or processes were in place. By 2011-12, when a public relations position was created for the libraries, more than 20 people had posting permissions. Despite the deep talent pool, postings were sporadic and of varied quality. 
As the communications office took on more ownership for most media outlets, followers and page "like" numbers grew. The office tied some postings to planned campaigns or initiatives and collaborations with the University. At the same time, staff changes reduced the number of posters, and an informal moratorium on new accounts was briefly imposed and lifted in 2013.

At the start of the 2014-15 school year, the communications office began focusing on new media. First, it identified new viable platforms and worked with teams or individuals to develop clear content plans and objectives. Second, it began evaluating efficacy of existing platforms and revised content strategies, audiences and goals for each. Third, it evaluated which platforms might need to be merged with others or retired. Fourth, and this is the most sensitive issue, it considered who is responsible for management and content creation?

The planning and evaluation process is ongoing and has required a deep look at practices in governance, strategy, content, and planning among our library peers in order to provide a foundation for decision-making. Most importantly, we wanted to reflect on academic libraries' practices in the context of best professional communications and public relations practices.

\section{The 2015 VCU Libraries survey}

To get a sense of current practice in academic libraries, we reviewed the available library literature. We identified areas that required additional exploration and turned to public relations for guidance. Wright and Hinson conducted and reported on a ten-year longitudinal study on social media and public relations practice (2015). Their survey, which is directed at public relations practitioners, addressed areas of interest, so we modeled questions on their work, making adjustments for a library community. Our survey was then distributed to email discussion lists for library professionals involved in management or communications. Of the 240 
responses, 200 (88.5 percent) were affiliated with academic libraries. For this analysis, we focus only on survey responses from academic librarians.

This article focuses on the data collected on platform use, governance practices, and content strategy and how it aligns with public relations practice. The complete survey and resulting summary data is available in VCU's institutional repository, Scholars Compass: http://scholarscompass.vcu.edu/

\section{Alignment in the use and importance of social media platforms}

Libraries' use of social media is well-documented in the library literature. Wan found that 90.4 percent of ARL libraries had a Facebook page (2011), and Chu and Du found that 71.1 percent of the academic librarians they surveyed across Asia, North America, and Europe used social networking tools with Facebook and Twitter being the most popular (2013). A more recent white paper from Taylor \& Francis Group reports similar findings; 70 percent of the librarians considered the use of social media tools important. It also confirmed that Facebook and Twitter remain the most popular platform for libraries, but libraries are also using blogs and investigating visual platforms such as YouTube, Pinterest, Flickr, and Instagram (2014).

Librarians are aligned with public relations professionals in terms of the use and ranking of importance of social media platforms. Wright and Hinson found Facebook and Twitter were the most used and important platforms in public relations practice (2015), and our results confirmed the same for libraries. Ninety-three percent of our respondents found social networks such as Facebook very important or somewhat important to their library's communication strategy, and 79 percent found microblogging such as Twitter very important or somewhat important. Libraries also have keen interest in video and photo content sharing sites, and Wright and Hinson found the same for platforms like YouTube and Instagram (2014). 
Academic libraries are also in sync with public relations best practices using management tools like Hootsuite and Tweetdeck. Our survey found 42 percent claimed these tools somewhat important or very important, and 25 percent used Hootsuite frequently or very frequently. Other tools such as Tweetdeck, Buffer, and SproutSocial were also mentioned. These tools are also favored by public relations professionals as indicated by the Wright and Hinson study that found that 40 percent of public relations professionals use Hootsuite frequently or very frequently (2015).

\section{Disconnects in social media management}

Despite the documented prevalence and perceived value, the current state of social media use by libraries can be characterized as "ad hoc and somewhat experimental" (Taylor \& Francis Group 2014). Wan found postings were sporadic with limited reach, and that they were often focused on event promotion (2011). While the Taylor \& Francis Group found that the frequency of posts is increasing with 30 percent of their respondents posting daily, they confirmed that the promotion of events, resources, and services is still the top objective for libraries (2014).

Witte cautioned that the "...content academic libraries most want to promote may in fact be the information to which users are least likely to respond" $(2014,95)$. While the potential of social media to connect with users is an often cited benefit (Taylor \& Francis Group 2014), engagement remains minimal. Gerolimos studied posts from 20 academic libraries and found that 63 percent had no interaction, and 91 percent had no comments (2011). It is concerning, given this reported lack of interaction, that 83 percent of our respondents spend five hours or less on engagement activities.

Our survey confirmed that social media are primarily integrated in communication strategies with events (85 percent) and other media for news and announcements (72 percent). 
Considering the bigger picture, our data reveals that few libraries 1) have a written policy (33 percent); 2) define tone for posts (34 percent); 3) define audience and purpose (30 percent); or 4) define a content and identity for each platform ( 25 percent). There is obvious room for growth in decision-making about content and audiences.

Library and public relations practices diverge in the area of management. As might be expected from PR professionals, the Wright and Hinson study reported that 74 percent of practitioners thought the communications and public relations position should be in charge of social media with another 14 percent reporting a dedicated digital or social media position (2015). In libraries, this function is often decentralized or managed by committee. The Taylor and Francis Group study found 44 percent of responses indicated the involvement of three or more team members (2014). Our study found the same: 46 percent of responses indicated that even when one person manages communication, others are deeply involved; 84 percent indicated multiple people had permission to post.

Academic libraries are not necessarily using tools to measure the impact of social media. While the Taylor \& Francis Group study did find that 71 percent of their respondents envisioned spending more time assessing the impact of social media in the future, they also found "it was not felt to be a priority to devote significant resource [sic] to trying to measure impact" (2014, 22). Our survey indicated that only 27 percent of respondents have a system of evaluation and measurement to determine the effectiveness and time invested in media management and posting. In comparison, Wright and Hinson reported more than half of the public relations professionals are measuring the impact and other outcomes of social media communication (2015). The comparison of communications and public relations with library 
practices provides some insight that suggests areas of focus for VCU Libraries and other academic libraries.

\section{Anticipate constant change and plan accordingly}

Open-ended questions and comments captured broad thinking among academic libraries' social media managers. An underlying theme seems to be waiting-and-seeing before jumping on a new platform. One respondent articulated the preference "to keep the library on longstanding social media" such as Facebook, Twitter and maybe Instagram, "rather than jump on trends like Snapchat."

Many also reported thoughts about revamping content or stepping back from Facebook's aging audience. As one respondent stated: "platforms are constantly changing and people are not locked into just one platform...I think it is important to be open to other platforms taking over and to be aware where our audience is." More than half of the respondents rated media such as Snapchat and YikYak as very unimportant. Snapchat's popularity and relevancy among teens were noted in many comments.

Prioritizing the idea of change when planning media strategy will empower libraries to make informed decisions about creating or retiring platforms that fail to meet quality standards.

\section{Know your numbers and focus on what matters most}

It was affirming that academic libraries' priorities generally aligned with the public relations data. Focusing on the platforms that matter most to users was a key theme. These commonly valued platforms include Facebook, Twitter, YouTube, and Flickr, with Instagram noted as an up-and-comer.

Clearly, not every institution should be using every media platform. Time and human resources are limited and some types of content are unique to different libraries. As libraries 
begin to embrace one platform, often a decision must be made to abandon another. One respondent succinctly described their library’s future strategy as, "less [P]interest, more [I]nstagram."

Do less better also seems to be a theme. For example, one respondent was scaling back to "clearly define the goals of those we keep," and another "would like to remove unused accounts...and focus on platforms where we have more impact." This thinking certainly applies to VCU Libraries, which is evaluating its twenty-plus channels to determine which should be kept, and other libraries are likely considering similar actions.

\section{Who is in charge?}

Libraries largely rely on a decentralized system of social media posters. Libraries are unique and complex institutions, so it is not surprising that this would be a departure from public relations practice. If there is a position dedicated to public relations and communications, it is important to develop management practices that facilitate collaboration and flexibility to support all of the voices in an academic library. This requires a coordinated approach that includes content strategies, writing style guidelines, an editor or team for each platform, and editors managing platforms on a day-to-day basis. These approaches strive to align all content creators in common practices that support the libraries and institutional priorities.

\section{Who is your reader?}

Libraries use social media because of its potential to create closer relationships with library users. Relationship building is the crux of public relations. Many of our respondents cited increasing engagement as both a goal and a challenge. One comment echoed the concern in the literature about "our biggest challenge is getting more engagement in our platforms, rather than just using these for announcements." In this area, libraries lag behind public relations 
professionals, many of whom are measuring impact and other outcomes (Wright and Hinson 2015, 10-12).

Engagement--consumption, sharing, comments, response to calls-to-action, "likes” by users, growth of the audience--is critical. The quality of our content may be excellent but if no one is responding, is this wise stewardship of our human resources? One possible reaction to lack of engagement is moving content to a more static medium, such as a blog or research guide or web page. For some types of library information, these platforms may see more return consumers than through the ephemeral and fleeting scope of new media.

\section{Moving toward a more robust content strategy}

Best practices in public relations call for setting objectives, goals, and planning. Planning is a constant in public relations circles. Our survey found that few libraries are developing content strategies with defined audiences, purposes, or tone, and many comments either echoed the lack of a strategy and/or the desire to define strategy in the future. As one of our respondents commented: "It is best to develop a content strategy before beginning any new channel."

Content strategy is a term widely used among web developers as well as public relations and marketing practitioners. Halverson offers a concise, clear, and readable definition that was written for a user experience audience but applies to all digital content:

Content strategy plans for the creation, publication, and governance of useful, usable content. Necessarily, the content strategist must work to define not only which content will be published, but why we're publishing it in the first place. Otherwise, content strategy isn't strategy at all...At its best, a content strategy defines: key themes and messages, recommended topics, content purpose...content gap analysis, metadata frameworks and related content attributes, Search Engine Optimization (SEO), 
and...strategic recommendations on content creation, publication, and governance (2008).

VCU Libraries uses a "content strategy" creative brief for each of its new social media platforms. We are also in the process of reviewing all outlets and developing a strategy document that spells out the substance, structure, governance and workflow of these communications products. Our research points us toward a more robust system of planning and managing our social media. We are exploring using the Content Strategy Alliance's newly published (free for download) toolkit that provides tried-and-true templates for many content and workflow best practices (2015).

\section{Embracing key public relations practices}

In order to build a stronger content strategy for our new media, two added baseline best practices from public relations should be applied. First, evaluation is essential, and objectives and goals should set as part of an enhanced planning process for creating new platforms. Our research shows that few libraries rely on analytics, yet it is essential in measuring success. Goal setting and planning must be thoughtful and "should not be at the expense of stifling creativity or eliminating flexibility.” (Watson and Noble 2005, 159).

Second, we need to focus pointedly on relationships. Public relations by nature and by definition is all about managing the institution's different publics. Content and conversations can either connect with people or float unnoticed and unread in cyberspace. We need to explore more deeply who our social media consumers and followers are, and seek ways to engage them more actively=

\section{Recommendations}


We recommend libraries consider best practices in public relations as they look for the answers to their questions about social media planning. Two areas in particular are key to effectively and efficiently managing social media for academic libraries.

Creating content strategies will clearly articulate goals and intent for each platform. The content strategy is a living document, reviewed at least annually. Consider how to handle outcomes if goals and objectives are not met and how to determine if a channel should be retired or continued. Institutional self-interest and data, rather than individual interests, should guide both development of the strategy and decisions about a channel's future.

Evaluation is also essential and objectives and goals should be part of a planning process for maintaining or creating new platforms. Currently few libraries rely on analytics for decisionmaking about platforms. This presents an area for growth and improvement. Do not fear making difficult decisions, about retiring channels or saying "no" to new proposals. Human resources are limited and we may well be able to do more with less, with fewer channels and demands on time-starved content curators.

This cycle of goal setting and evaluation provides libraries with a strong foundation for decision-making and allows for continued adaptation in an evolving social media landscape, ultimately building stronger connections with users.

\section{References}

Chu, Samuel Kai-Wah and Helen S. Du. 2013. "Social Networking Tools for Academic Libraries.” Journal of Librarianship and Information Science 45(1): 64-78, doi: 10.1177/0961000611434361.

Content Strategy Alliance. 2015. Tools \& Template: A Best Practices Handbook. http://contentstrategyalliance.com/csa-best-practices/csa-handbook/ 
Gerolimos, Michalis. 2011. “Academic Libraries on Facebook: An Analysis of Users’ Comments." D-Lib Magazine, 17(11/12). http://www.dlib.org/dlib/november11/gerolimos/11gerolimos.html

Halverson, Kristina. 2008. “The Discipline of Content Strategy.” A List Apart. http://alistapart.com/article/thedisciplineofcontentstrategy

Taylor \& Francis Group. 2014. Use of Social Media by the Library: Current Practices and Future Opportunities. http://www.tandf.co.uk/journals/access/white-paper-social$\underline{\text { media.pdf }}$

Wan, Gary. 2011. "How Academic Libraries Reach Users on Facebook." College \& Undergraduate Libraries 18(4): 307-318, doi: 10.1080/10691316.2011.624944.

Watson, Tom, and Paul Noble. 2005. Evaluating Public Relations: A Best Practice Guide to Public Relations Planning, Research \& Evaluation. London: Kogan Page Limited.

Witte, Gina Gauntner. 2014. “Content Generation and Social Network Interaction within Academic Library Facebook Pages.” Journal of Electronic Resources Librarianship 26(2): 89-100, doi: 10.1080/1941126X.2014.910356.

Wright, Donald K. and Michelle Drifka Hinson. 2015. "Examining Social and Emerging Media Use in Public Relations Practice: A Ten-Year Longitudinal Analysis.” Public Relations Journal 9. https://www.prsa.org/intelligence/prjournal/documents/2015v09n02wrighthinson.pdf 